MÉXICO: UNIVERSIDAD NACIONAL AUTÓNOMA DE MÉXICO

Mario Magallón Anaya Juan de Dios Escalante Rodríguez, (2014)

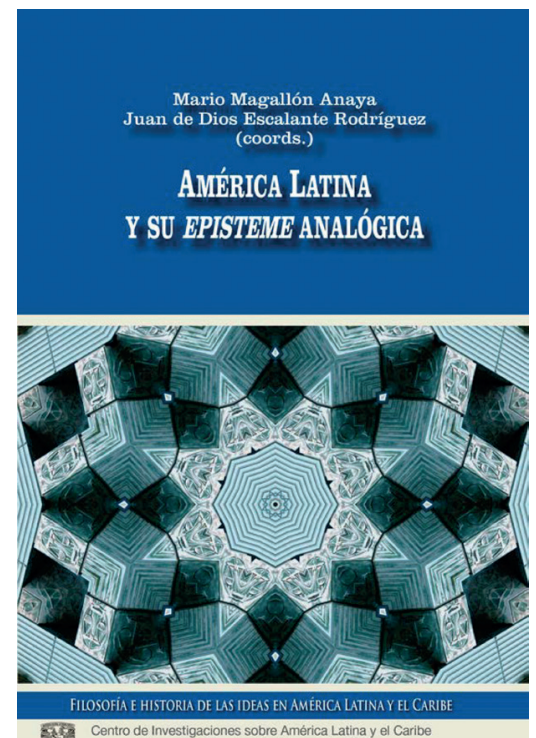

1. Centro de Investigaciones sobre América Latina y el Caribe
Universidad Nacional Autónoma de México

\title{
América Latina y su episteme analógica
}

\section{YOANA FLORES HUELLACO}


América Latina siempre cuidando al Otro". Se ajustan y describen el panorama de lo que tenemos en común: un escenario de violencia, de negación, individualización, de fragilidad emocional, de diversidades tanto económicas, políticas y culturales; en segundo lugar trascender la filosofía como aquella que se reducía a los grandes (desde el origen occidental) a los contextos más comunes donde hace falta explicar y reflexionar "el Ser"; a partir del contexto propio, una generación epistemológica, que utiliza hermenéutica analógica (Beuchot), como lo explican los autores, no se trata de hacer a un lado lo construido, sino aprovecharlo, para dar paso a la filosofía de la posmodernidad, "siempre despertando lo que el conocimiento había venido escondiendo y velando".

Magallón Anaya y Escalante Rodríguez se dan a la tarea de recopilar una serie de investigaciones encaminadas a la reflexión, propuesta y construcción de una nueva filosofía, una que explique y retome la historicidad de lo que nos rodea y nos ha rodeado. Cada lectura es resultado de una investigación colectiva, producto del Centro de Investigaciones sobre América Latina y el Caribe, CIALC/UNAM; proyecto denominado: Diversidad filosófica en América Latina. Segunda mitad del siglo XX.

En este libro se presenta a México y Latinoamérica como portadores de una contribución filosófica que hasta el momento es muy poco conocida, nos invitan a vivir la historia de la filosofía contemporánea, retomando a pensadores como: Leopoldo Zea, José Gaos, Luis Villoro, Horacio Cerutti, etc. Haciendo referencia a la frase "estamos tan cerca y no nos comunicamos", en efecto, como lo mencionan, no se conoce y muy poco se ha aprovechado la fuente filosófica que se tiene en Latinoamérica, pero en este texto se justifica a partir de la hermenéutica analógica y la construcción del ethos barroco, un punto de partida de nuestro acontecer latinoamericano.

En América Latina y su episteme analógica se categorizan producciones relacionadas a la filosofía, la cultura, la interculturalidad, la educación y algunos pensadores filosóficos; se dará un breve recorrido, enfatizando conceptos e ideas claves que nos aportan una construcción sistemática de la explicación e historicidad de la realidad.

Mario Magallón Anaya, Ana Claudia Orozco Reséndiz, Juan de Dios Escalante Rodríguez y Tezkoatl Mitzin Pérez Alvarado construyen un primer apartado “Tradición epistemológica en la historia de las ideas", se puede percibir una interrelación que cruza entre las investigaciones presentadas, encaminados a la filosofía y la historia de las ideas.

La razón, la filosofía y la cultura, no son cuestión de moda, como lo quieren hacer ver algunos posmodernos, es una búsqueda permanente de reflexión, de análisis y críticas sobre problemas más relevantes: la existencia de la vida, el ser, la ética, la verdad, la sociedad, la historicidad, la ciencia, la tecnología, la ecología, así como el futuro de la humanidad. Es imperante la reformulación de una nueva filosofía desde la perspectiva del contexto propio e ir erradicando "irracionalidad y totalitarismos", esas prácticas autoritarias, para poder encontrar salidas de producción humana, social y cultural sustituyendo a las "dominantes en la actualidad".

Entender la modernidad filosófica y cultural como "una forma expresiva y práctica de la razón" es imperante para relacionarla dentro de un contexto socio- histórico, entendiendo que solo es el producto de una temporalidad espacial. Magallón Anaya brinda la reflexión “no sólo sobre cuestiones del método sino además de relaciones metodológicas, elaboraciones teórico- formales, problemas epistemológicos, construcciones de lenguajes significativos y su 
valor simbólico, arquitecturas de sentido y de significación; todo lo cual que ser visto desde el ámbito de la realidad sociohistórica". Un filosofar que sea funcional para la vida, acredita la idea de Kant "disipar los engaños producidos por la mala inteligencia", aunque sea necesaria la destrucción, es mejor retomar las ideas de Magallón y Escalante, darle utilidad a todo lo construido, lo que nos sirva, para una nueva significación, justificando que no existe una historia única.

Orozco Reséndiz reafirma que las propuestas del filosofar latinoamericano están basadas en las "crisis constantes", que invaden actualmente a la sociedad un "filosofar situado"; rescatando la verdad y la historicidad como fuente para retomar las preocupaciones que atañen a la vida social, política, económica y cultural de nuestra América.

Haciendo referencia al legado Leopoldo Zea "desmitificar las falsas características del filosofar latinoamericano" es un compromiso y responsabilidad, estudiar más a fondo las ideas latinoamericanas desde la interdisciplina, ya que no se puede aislar, es necesario movilizarla tanto para su análisis y construcción, manejando siempre una reflexión con ética y una verdadera toma de conciencia en la crítica de los acontecimientos, para que la humanidad pueda "aprehenderla y comprenderla".

El ser humano desde su existencia ha tenido la inquietud de saber todo lo que pasa y ha pasado a su alrededor, su acontecer histórico, social, político, etc. Más complejo aún, cómo se han expresado e interpretado su realidad. Juan de Dios Escalante Rodríguez formula una reconstrucción de la "historia de las ideas" compartiendo una explicación que nos lleva desde Platón, Hegel, Ortega, José Gaos, Leopoldo Zea, entre otros.

"Sustancialidad y causalidad" son las características que deben tener las ideas que nos interesan -históricas- ya que dan vitalidad en la existencia óntica y fenoménica, en ellas se centra este artículo, las sitúa en espacio y tiempo en América Latina. Para entender el acontecer sociohistórico es imperante remontarse siglos atrás, desde la llegada de los españoles y reflexionar que ese fue uno de los parte aguas para entender diversos ámbitos que van desde lo cultural, político y social. Analizar la proyección e implantación del sometimiento y la opresión sobre los habitantes de Latinoamérica, explicar lo europeo con la acción en circunstancia, saber qué elementos teníamos y reconstruir el pasado. "La tradición de historiar las ideas tiene un fin humano porque ellas son el espejo de lo que el ser humano actúa en lo cultural y toma de conciencia de sí en su ambiente e historia", acción que busca la emancipación y dar sustento a la libertad, para encontrar "caminos propios para los habitantes de América Latina" una verdadera apertura al cambio social y político, que sirva de algo esa historia reflejada en "sangre, resistencias, huelgas, muertes y protestas". No se describe solo "un pedazo de la realidad "como se podría pensar, ya que es evidente que México y América Latina son el fruto de lo antes descrito y como bien expresa el autor" la historia no se ha acabado de escribir".

Interdisciplina, pedagogía, educación y política son requeridos para que la historia de las ideas no sólo quede en discurso, el fin último es trascender la circunstancia, por ello surge la necesidad historiográfica para conocer el pasado. Se defiende la posición del filosofar latinoamericano retomando a Leopoldo Zea y José Gaos resumiendo claramente en la siguiente idea "El pasado no interesa por él mismo. Últimamente sólo interesa para construir el presente y el futuro. El presente es la única realidad. En él que han de hacerse más o menos reales el pasado y el futuro". 
Finalmente, en el artículo de Pérez Alvarado plasma la necesidad de conocer la importancia de la filosofía en la vida y en la actualidad. Reflexiona que no se vea como una actividad "inútil e inconsecuente", por el contrario, nos lleva de la mano a una explicación teórica y socio histórica, la cual radica en analizar la sociedad productivista, donde todo se ha materializado en los objetos que podemos ver, palpar y contar. La filosofía es trascendental para el hombre "porque su razón, no es producir ni explotar, sino mejorar la estancia del hombre sobre el mundo".

Compara la filosofía con la metafísica, los argumentos de Pérez Alvarado se visualizan en una utilización profunda y metódica, retoma algunas aportaciones de Ellacuría, las cuales podemos evaluar son convincentes y nos llevan a razonar la importancia de la filosofía. Nos invita a reflexionar la filosofía, retomando algunas cuestiones desde el contexto occidental, si ésta solo es por vanidad intelectual. Surge la incógnita ¿si tal vez por formación cultural o meramente por presunción académica? Lo anterior no es filosofía, pues no se puede enseñar a filosofar desde otras realidades, es imperante, asimilar que no se debe enseñar desde construcciones prefabricadas desde "una alteridad no vivida", por el contrario, partir de la realidad. Justifican que la esencia de la filosofía es darle al hombre las herramientas necesarias para la construcción de su realidad: una más justa. Propone la responsabilidad de asumirse como "filósofos auténticos", como sujetos cambiantes y de cambio: "Podemos avocarnos a recuperar el sentido original del movimiento erótico que emociona al filósofo y lo conmueve a preocuparse por sus semejantes. En todos nosotros está la decisión de volver a amar al mundo o matarlo para siempre"

En un segundo apartado denominado "Filosofía, analogía y cultura en América Latina”, después de haber justificado ampliamente la historia de las ideas a través de qué es, cómo es y dónde; poniendo en práctica la acción de filosofar. Nos comparten artículos que entrelazan cosmovisiones más locales: filosofía maya a partir del análisis de dos pueblos en particular. tzotziles y tojolabales.

Gabriela Jurado manifiesta que hay posibilidades -aún- de que no se consideré filosofía desde el pensamiento y vivencias de estos pueblos, sin embargo, confirma que nuestra América y México son lugares que por historicidad se definen como multiculturales y la manera de comprender el mundo y la realidad es a partir de centrarnos en contextos concretos y sus características: dignos representantes de vivencia, sabiduría y tradición; "nosotros" y "comunidad" dan la base de la organización y el bien de un todo, una apropiación de asumirse éticamente como parte de la relación con lo que somos: "reconocimiento consiente de alguien más con quien participo en la vida". Una comunidad que práctica una filosofía de vida integradora para todo aquel que quiera participar en ella "una vida más justa" uno de los objetivos de esta filosofía.

Lucía de Luna Ramírez incorpora una alternativa que se presenta con características diferentes al modelo neoliberal. Una propuesta que va encaminada a la inclusión desechando un proyecto económico individualista.

Una de las mayores aportaciones que se puede rescatar es la explicación de la filosofía indígena, la mirada que ambas autoras vuelcan hacia el otro, hacia el diferente, hacia esas minorías que por décadas han sido desterrados de su origen, de su espacio y de sus maneras de vivir. Se ve plasmado no sólo el reconocimiento de esas comunidades, sino aún más, la oportunidad de reflexionar y analizar su realidad para llevarla a otros contextos, para darla 
a conocer. Retomando textos de Lenkersdorf y León Portilla "replantear una práctica de liberación que tenga como base la filosofía de los pueblos originarios".

La interculturalidad se incorpora a este cúmulo de saberes, para complementar un análisis más exhaustivo fundamentado en que los investigadores de disciplinas humanísticas y sociales han demostrado las diferencias de grupos y promover el respeto a las manifestaciones culturales, en particular a pueblos nativos, inmigrantes, comunidades religiosas y otros tantos grupos que comparten rasgos culturales. Miriam Díaz Somera utiliza la hermenéutica analógica para dar sentido, fundamentación y argumentación, para aceptar que no hay un solo modelo cultural que deba hegemonizar a las sociedades.

América Latina ha ido construyendo su propia identidad, la cual pone en el tintero Elías Israel Morado Hernández si ésta ¿ha sido violentada? Las respuestas al azar podrían ser muy rápidas y con una justificación que es evidente en el acontecer histórico. En este artículo se hace una discusión sobre la cultura y el barroco, retomando a Bolívar Echeverría, exponiendo "claves" como las que a continuación se presentan: "barroco", "violencia" "modernidad", "capitalismo" "identidad" y "mestizaje" donde explica una correlación, la cual da como resultado a una "condición de vulnerabilidad" en la que es necesaria una "reorganización sociopolítica" que beneficia principalmente a la reproducción del capital, situación en donde es imprescindible la violencia.

Un tercer apartado "Filosofía y educación en América Latina" en el que se hace una connotación sobre la educación, la interculturalidad, la resistencia, la formación y la Alteridad. Autores que retoman a grandes pensadores para dar explicación a las teorías, aportaciones y propuestas investigadas.

Mariana Aguilar Bobadilla y Gabriela Vallejo Hernández mencionan que, desde el ámbito educativo, se gestan políticas y soportan un cambio que sustentan la diversidad cultural como hecho social en el que se generan discriminación y dominación, por lo que es de índole importancia reformular los programas curriculares y la formación docente. Se mira a la educación como el punto donde convergen "las diferencias en el ámbito de la cultura y pone énfasis en los cambios generados en todos los ámbitos de la sociedad". La visión interdisciplinaria se pone en perspectiva, no perder de vista a la escuela como un "espacio social en disputa" donde existe la exclusión, discriminación, integración, diferencias, diversidad, tensión social, diálogo, comunicación, negociación, convivencia y resignificación. - el espacio justo para significar los conceptos y movilizarlos hacia la práctica-.

La interculturalidad, así como la filosofía para niños son formulaciones que se encuentran en proceso de investigación y aunque ya se han establecido en diversos países de Latinoamérica como México, es imperante seguir en ello. La práctica de estas propuestas nos ofrece para los habitantes de cada comunidad una aportación invaluable al modo de vivir: pensamiento crítico, creativo y moral, sociedades con razonamientos más lógicos, sensibles, vivir en equidad, democracia social solidaria y deliberada.

Piedras Arteaga y Pérez Sevilla plantean la necesidad de repensar que el problema no es cambiar la "conciencia", el verdadero problema es modificar "el régimen político, económico, institucional de producción de la verdad" y reconocer las verdaderas posibilidades a las que nos encontramos al hablar del otro, en la descripción de la alteridad, nos comparten su reflexión ante el encuentro con la diferencia. 
Finalmente, en el último capítulo Magallón Anaya y Escalante Rodríguez hacen una recopilación de investigaciones sobre pensadores Latinoamericanos que se han quedado en el olvido del filosofar, tanto a nivel mundial como de manera local. En estos últimos artículos se justifica que lo ya existente (occidental) no se desecha, ni se ignora, por el contrario, sirve como punto de comparación con la realidad que ven nuestros filósofos latinoamericanos. Desde Platón hasta Antonio Gómez Robledo, Antonio Caso, Arturo Andrés Roing y Gallegos Rocafull, en letras de Alfonso Vela Ramos, María Esther Ofelia Posadas Ortiz, César Miguel Sandoval Laurrobaquio Alvarado y José Leonel Vargas Hernández nos presentan un cruce disciplinario.

El libro América Latina y su episteme analógica sin duda nos ofrece grandes aportaciones no sólo como disciplina, es decir de manera aislada, si no confirma hasta el final que es un texto que brinda de manera fácil y clara herramientas para entender la realidad, recoge el hoy de "nuestra América"; nos brinda la temporalidad actual; que ofrece la reflexión del "ser desde los problemas que atañen a la sociedad. Definitivamente un libro que aporta de manera general una contribución al estudio de la "historia de las ideas" pero que confirma también que en México se sigue y seguirá produciendo contenido de filosofía: los autores de estos artículos se muestran como filósofos del siglo XXI poniendo en alto a los grandes pensadores latinoamericanos. 